Revista Brasileira de Geomorfologia

v. $19, \mathrm{n}^{\circ} 3$ (2018)

www.ugb.org.br

ISSN 2236-5664

http://dx.doi.org/10.20502/rbg.v19i3.1287

\title{
ANÁLISE DO IMPACTO DO DESMATAMENTO NO APORTE SEDIMENTAR DE BACIAS PAREADAS NA AMAZÔNIA OCIDENTAL: BACIAS DO RIO MUTUM-PARANÁ, RONDÔNIA (BRASIL)
}

\section{ANALYSIS OF THE IMPACT OF DEFORESTATION ON THE SEDIMENT YIELD OF PAIRED BASINS IN WESTERN AMAZÔNIA: BASINS OF THE MUTUM-PARANÁ RIVER, RONDÔNIA (BRAZIL)}

Michel Watanabe

Departamento de Educação do Campo, Universidade Federal de Rondônia Avenida Norte Sul, Porto Velho, Rondônia. CEP: 76940-000. Brasil

E-mail:michelwatanabe@unir.br

Fabiano Antonio de Oliveira

Departamento de Geografia, Universidade Federal do Paraná Centro Politécnico, Jardim das Américas, Curitiba, Paraná. CEP: 81531-990. Brasil E-mail:foliveira@ufpr.br

Dorisvalder Dias Nunes

Departamento de Geografia, Universidade Federal de Rondônia BR-364, Km 9,5, Porto Velho, Rondônia. CEP: 76800-000. Brasil

E-mail:dorisval@unir.br

Adriana Cristina da Silva Nunes Departamento de Arqueologia, Universidade Federal de Rondônia BR-364, Km 9,5, Porto Velho, Rondônia. CEP: 76800-000. Brasil E-mail: adriananunes13@hotmail.com

Maria Madalena de Aguiar Cavalcante Departamento de Geografia, Universidade Federal de Rondônia BR-364, Km 9,5, Porto Velho, Rondônia. CEP: 76800-000. Brasil E-mail:mada.geoplan@gmail.com

Tamires Cunha de Aguiar

Departamento de Geografia, Universidade Federal de Rondônia BR-364, Km 9,5, Porto Velho, Rondônia. CEP: 76800-000. Brasil 


\section{Informações sobre o Artigo}

Data de Recebimento:

28/02/2018

Data de Aprovação:

$17 / 03 / 2018$

\section{Palavras-chave:}

Sedimentos em Suspensão;

Bacias Pareadas; Amazônia;

Hidrossedimentológico.

\section{Keywords:}

Suspended Sediment;

Paired Basins; Amazônia;

Hydrosedimentological.

\section{Resumo:}

O artigo propôs analisar os impactos do desmatamento na dinâmica de sedimentos em suspensão de bacias pareadas do rio Mutum-Paraná, Norte do país, Estado de Rondônia, com base na relação chuva-vazão-sedimento-turbidez, a partir da intensificação do uso e da cobertura da terra. Foram realizados registros horários de eventos de chuva específicos dos parâmetros hidrossedimentológicos: vazão, turbidez e coleta de amostras de água para quantificação de sedimentos em suspensão, somada à coleta de dados pluviométricos por meio de estação hidrométrica automática. Os resultados obtidos mostraram regulação dos parâmetros vazão, turbidez e sedimento em suspensão de três bacias denominadas: bacia Floresta, bacia Pecuária e bacia Mutum-Paraná. Dentre os parâmetros hidrossedimentológicos analisados, as variáveis sedimento em suspensão e turbidez apontaram forte a muito forte correlação. A análise da carga sedimentar nos eventos pluviométricos mostrou-se com índices significativos, apresentando valores de sedimento em suspensão elevados na bacia Pecuária, com valores de

$2.961,90$ ton/ano e vazão de $3,06 \mathrm{~m}^{3} / \mathrm{s}$ em 21 de dezembro de 2014, bem como 1.721,23 ton/ano e vazão de 1,83 $\mathrm{m}^{3} / \mathrm{s}$ em 31 de janeiro de 2015, o que corresponde, respectivamente, a 35\% e 53,7\% de carga sedimentar a mais em relação à bacia Floresta.

\begin{abstract}
:
The article proposes to analyze the impacts of deforestation on the suspended sediment dynamics of paired basins of the Mutum-Paraná River (northern Brazil, state of Rondônia) based on the rain-flow-sediment-turbidity ratio and the intensification of the use and the cover of the land. The occurrence times of specific rain events were recorded regarding the hydrosedimentological parameters of flow, turbidity, water samples collected for suspended sediment quantification and rainfall data collected by an automated hydrometric station. The results showed regulation of the flow, turbidity and suspended sediment of the Floresta, Pecuária and Mutum-Paraná basins. Among the hydrosedimentological parameters analyzed, suspended sediment and turbidity indicated a strong to very strong correlation. Analysis of the sediment load in the rainfall events presented high suspended sediment values in the Pecuária Basin of 2,961.90 tons/year and a flow of $3.06 \mathrm{~m} 3 / \mathrm{s}$ on December 21, 2014 and 1,721.23 tons/year and a flow of $1.83 \mathrm{~m} 3 / \mathrm{s}$ on January 31,2015 , which corresponds, respectively, to a $35 \%$ and $53.7 \%$ larger sediment load than the Floresta Basin.
\end{abstract}

\section{Introdução}

Nas últimas três décadas, a intensificação do uso da terra na Amazônia tem se desenvolvido, principalmente, pela atividade agropecuária, com consequências para todo o sistema ambiental (RIVERO et al., 2009; NUNES et al., 2015). Tais impactos gerados pelo desmatamento propiciam a redução da infiltração de água no solo e, por conseguinte, o aumento do escoamento superficial, desencadeando, muitas vezes, fluxo torrencial sob fortes chuvas, favorecendo o desenvolvimento dos processos de erosão do solo que conferem maior carga sedimentar ao fluxo de água nos canais fluviais.

Assim, torna-se fundamental o entendimento dos elementos e dos processos geomorfológicos que definem a carga sedimentar dos rios. Na Amazônia, as cargas sedimentares dos rios são bem elevadas, com média de 800 milhões de toneladas por ano, mesmo em ambiente mais plano, explicado pela característica sedimentar da bacia, associada à região Andina e seus rios de grande porte, com destaque para a bacia do rio Madeira, na qual se insere a área de estudo, cujo aporte sedimentar é 45\% do total da bacia Amazônica (FILIZOLA; GUYOT, 2011) - cenário que exige melhor entendimento dos elementos e processos geomorfológicos que definem a carga sedimentar dos rios.

Ao considerar as peculiaridades de cada região, pode-se aferir o grau de complexidade do sistema fluvial, uma vez que os rios são poderosos agentes geomorfológicos capazes de erodir, transportar e 
depositar elementos (CHRISTOFOLETTI, 1981). Cada etapa de formação de um rio está associada à morfogênese do relevo, o que pode determinar o maior ou o menor grau de intensidade de processosrespostas das componentes hidrológicas, como o sistema morfológico de canais, vertentes, planícies de inundação e a dinâmica da descarga líquida e sólida (PIÉGAY; SCHUMM, 2003).

Entender o rio como um sistema aberto com partes inter-relacionadas nas quais fluem matéria e energia, induz à busca por um equilíbrio entre as variáveis hidrossedimentológicas (CHORLEY, 1962). Mesmo apresentando superfícies e tamanhos idênticos ou similares, Tricart (1960) destacou que duas bacias podem apresentar vazões bem diferentes, justificado pelo tipo de solo e pela estrutura geológica. As quantidades de sedimento em suspensão podem apresentar grandes diferenças em virtude da predominância ou da ausência de cobertura vegetal que promova um retardo na infiltração e, consequentemente, controle no escoamento superficial (BECKINSALE, 1973).

A grande quantidade de rios da região propicia, de modo crescente, o desenvolvimento de estudos hidrossedimentológicos em escalas espaciais e temporais diferenciadas. Na Amazônia sul-ocidental ainda é incipiente a abordagem geomorfológica para o entendimento da dinâmica hidrossedimentológica de bacias pareadas. Estudos comparativos sobre o tema, como no caso de bacias pareadas, tornam-se cada vez mais importantes para compreender a dinâmica da paisagem (WATANABE, 2015).

O estudo de bacias pareadas envolve, pelo menos, duas bacias experimentais com características similares em termos de área, clima, aspectos geomorfológicos, pedológicos e de cobertura vegetal. A produção, o transporte e a deposição de sedimentos em bacias hidrográficas representam um dos fatos mais notáveis e complexos do sistema ambiental, sendo resultado da ação contínua de forças endógenas e exógenas no processo de modelagem da superfície terrestre (OLIVEIRA, 2006).

Destaca-se, ainda, que em bacias pareadas que apresentam características similares entre os fatores físicos, o comportamento de fatores hidrológicos e hidrossedimentológicos pode apresentar alterações, principalmente no que diz respeito à vazão (TRICART, 1960). Sendo assim, a hidrologia deve apoiar-se incondicionalmente sobre uma análise mais detalhada de todas as características físico-geográficas da bacia, apontando qual é a variável dependente e a independente. $\mathrm{O}$ estudo de bacias pareadas envolve, nas duas bacias experimentais alvo desse estudo, características similares em termos de declividade, orientação de vertentes, solos, área, clima e vegetação adjacente ou a proximidade de ambas (BROWN et al., 2005).

Diversos estudos (OLIVEIRA, 2006; VANACKER et al., 2007; VERICAT; BATALLA, 2006; SOLER; LATRON; GALLART, 2008; ESTRANY; GARCIA; BATALLA, 2009; LÓPEZ-TARAZÓN et al., 2010; DUVERT et al., 2010; TENA et al., 2011) tratam da comparação de bacias hidrográficas com as mesmas características físicas, com termos e conceitos desenvolvidos para tais análises. Neste sentido, optouse pela análise de bacias pareadas, com destaque para os trabalhos de Bosch e Hewlett (1982), Bruijnzeel (1990; 1996), Stednick (1996), Vertessy (2000), entre outros. Entretanto, para a Amazônia, poucos estudos foram desenvolvidos em bacias pareadas com enfoque geomorfológico; alguns, de caráter mais específico, unem técnicas para análise e avaliação de processos erosivos, conforme trabalhos de Silva Filho (2009), Watanabe (2011) e Nunes et al. (2015).

O objetivo da pesquisa consiste em analisar o impacto do desmatamento no aporte de sedimentos em suspensão de bacias pareadas do rio Mutum-Paraná/RO com base na relação chuva-vazão-turbidez-sedimento, a partir da predominância do uso e da cobertura da terra.

\section{Área de Estudo}

A área de estudo localiza-se à noroeste do Estado de Rondônia, na bacia do rio Mutum-Paraná, importante contribuinte do rio Madeira, que está em fase de transformação acelerada, impulsionada, nos últimos 10 anos, em virtude da construção das Usinas Hidrelétricas de Jirau e Santo Antônio (NUNES; CAVALCANTE; LOBATO, 2011; CAVALCANTE et al., 2011). No contexto hidrológico, a área de estudo situa-se na bacia do rio Madeira $\left(1,37 \times 106 \mathrm{~km}^{2}\right)$, correspondendo a 23\% da totalidade da bacia amazônica (GUYOT, 1993). São duas bacias experimentais analisadas, doravante denominadas como bacia Pecuária - bP $\left(43,26 \mathrm{~km}^{2}\right)$ e bacia Floresta - bF $\left(55,90 \mathrm{~km}^{2}\right)$, as quais compõem a bacia do rio Mutum-Paraná, conforme Figura 1. 


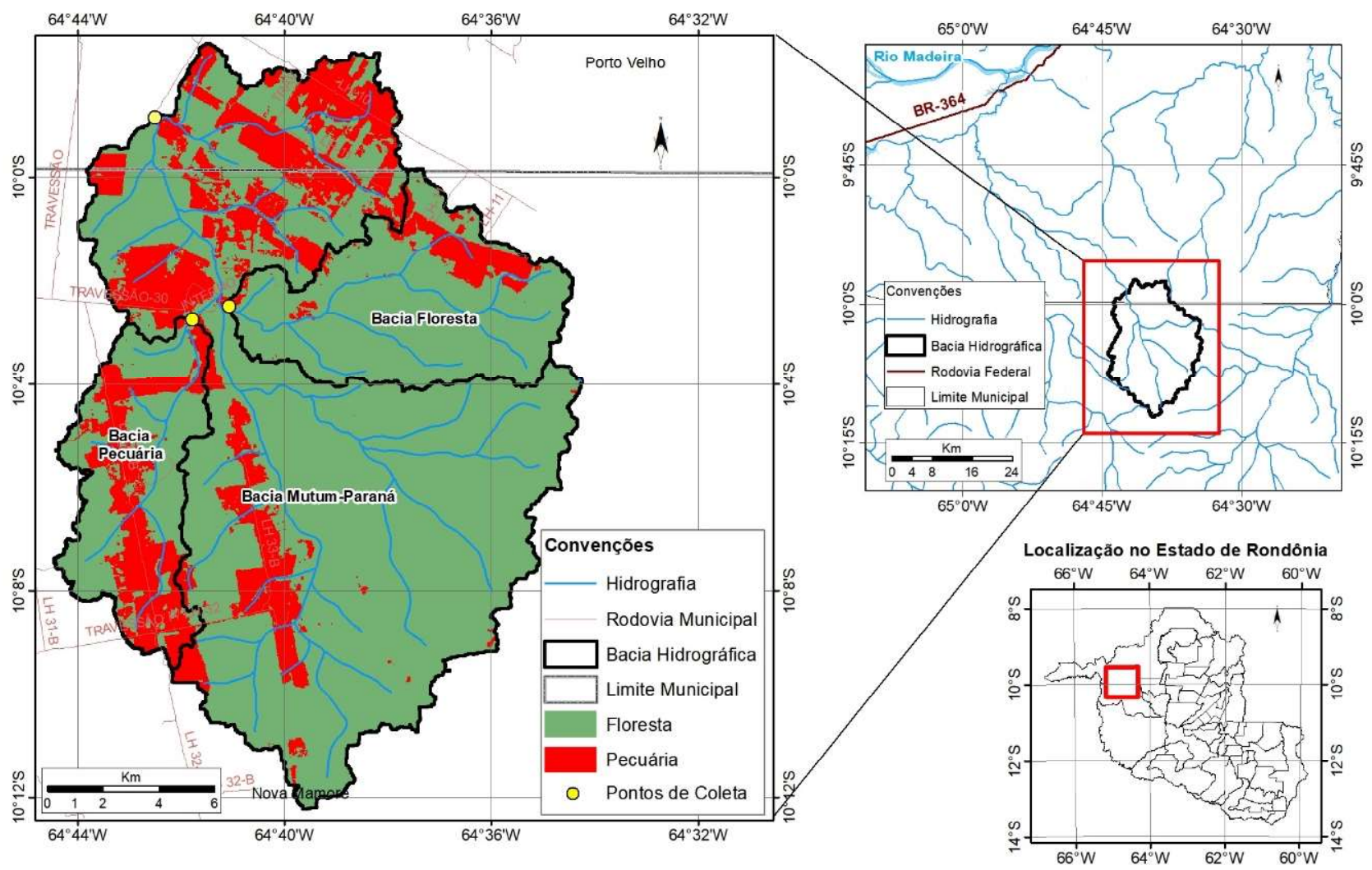

Figura 1 - Mapa de localização com uso da terra da área de estudo.

O domínio geomorfológico da região é caracterizado como superfícies de aplanamento, com vastas e extensas superfícies aplanadas, e elaboradas por meio dos processos de pediplanação. Tais superfícies podem variar altimetricamente de $100 \mathrm{~m}$ a $400 \mathrm{~m}$, principalmente na base de relevos residuais considerados como inselbergs. Apresentam dissecação elevada e nenhum ou esporádicos inselbergs e tors (agrupamento de morros), e correspondem ao conjunto de relevos com pouca expressão superficial. São consideradas como superfícies planas e seu aprofundamento dos vales é bem pequeno, normalmente inferior a $20 \mathrm{~m}$, sendo a densidade de drenagem caracterizada como alta e o padrão da drenagem do tipo dendrítico ou sub-dendrítico (TECNOSSOLOS, 2001).

De acordo com a classificação de Köppen, o clima na região é definido como sendo Aw - clima tropical chuvoso onde as taxas de temperatura média do mês mais frio são superiores a $18^{\circ} \mathrm{C}$ (megatérmico) e um período seco bem definido durante a estação de inverno, ocorrendo em Rondônia um moderado déficit hídrico com índices pluviométricos inferiores a $50 \mathrm{~mm} / \mathrm{mês}$ (TECNOSSOLOS, 2001). A área que compreende a região estudada possui variação de índices pluviométricos que podem oscilar de $1.800 \mathrm{~m}$ a $1.900 \mathrm{~m}$ anuais.

\section{Método e Procedimentos Operacionais}

O mapeamento temático utilizado como referência descritiva dos componentes ambientais foi o do Plano Agropecuário Florestal de Rondônia - PLANAFLORO (TECNOSSOLOS, 2001), na escala 1:100.000, visto ser esta a escala de mapeamento de melhor representação disponível para caracterização das especificidades das componentes ambientais.

\section{Dados Pluviométricos}

Para a análise da pluviometria foram utilizados dados de uma estação automatizada da marca Solar e modelo $S L 2000$, instalada no exutório da bacia Mutum-Paraná, com registros a cada 15 minutos no período de janeiro de 2013 a janeiro de 2015. Os dados foram obtidos com frequência horária, diária, mensal e anual, o que possibilitou a identificação dos eventos pluviométricos para uma melhor análise conjunta com outras variáveis hidrossedimentológicas. 


\section{Medidas de Vazões}

Nas bacias Pecuária e Floresta realizaramse medições com frequência horária nos dias 20 21/12/2014 e 30-31/01/2015 para registros de eventos pluviométricos específicos. As datas selecionadas foram pré-estabelecidas conforme a sazonalidade climática da região e que correspondiam a períodos de maior probabilidade de ocorrência de chuvas, conforme séries históricas analisadas na literatura. A disponibilização de apenas uma estação pluviométrica no local da pesquisa, a logística e a viabilidade da área de estudo definiram o caráter mensal das medições. As vazões foram medidas na calha principal dos rios, em trechos estáveis e de bom acesso (Figura 2). Na bP as medições foram efetuadas a partir de uma pequena ponte, e na bF adotou-se o método a vau. Em ambas as situações foi utilizada a técnica da meia seção, com velocidades tomadas por molinete hidrométrico posicionado em intervalos horizontais regulares, a $60 \%$ da profundidade local (SANTOS et al., 2001).

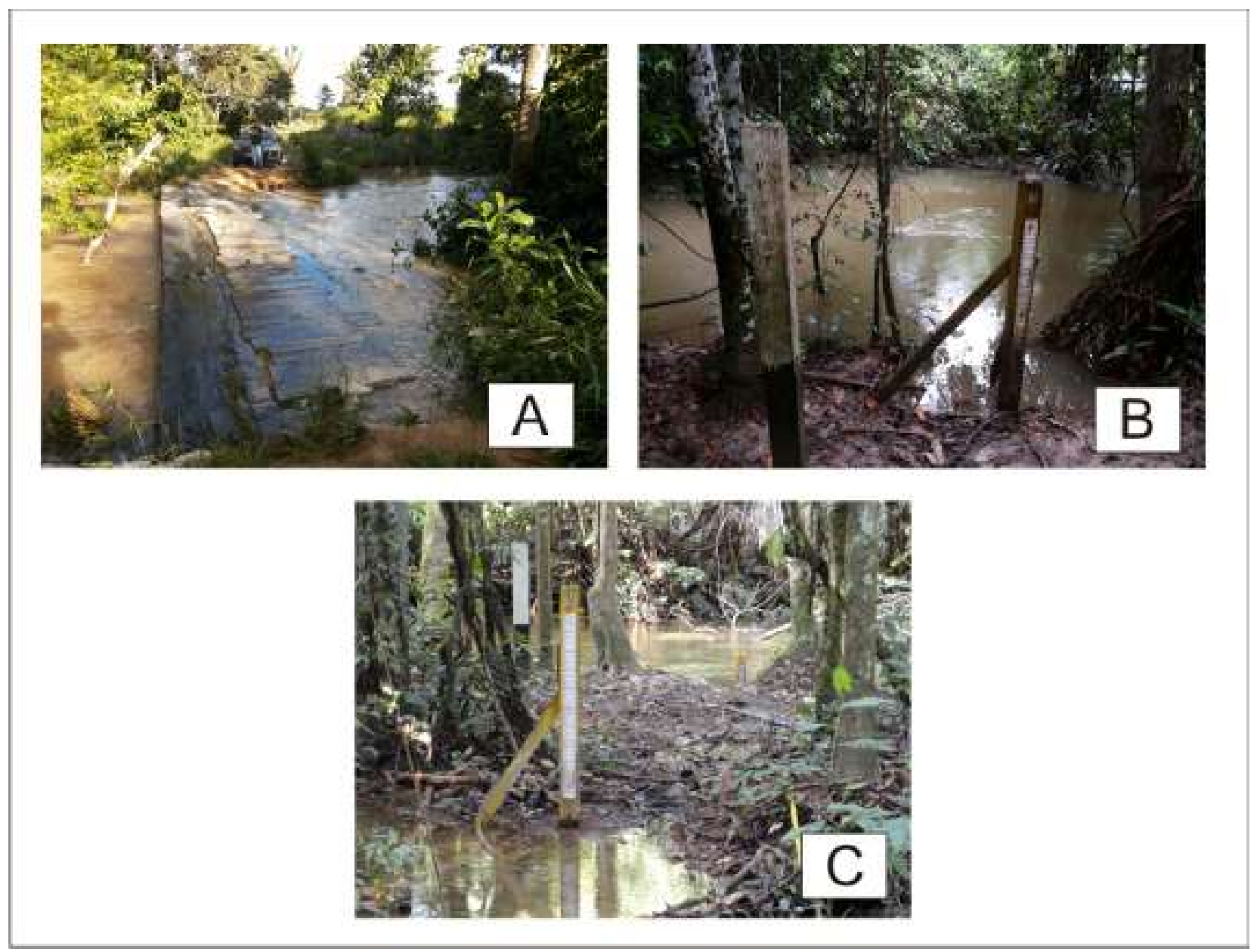

Figura 2 - Seções utilizadas para o monitoramento hidrossedimentológico.

\section{Coleta de Amostras de Água e Leitura de Turbidez}

As amostras de água foram coletadas com frequência mensal e horária por meio do método de Igual Incremento de Descarga (IID). Assim como as medições das vazões, as coletas de amostras de água ocorreram com frequência horária nos dias 20-21/12/2014 (48 amostras) e 30-31/01/2015 (44 amostras) para registros de eventos pluviométricos específicos e suas correlações.
O método IID ou EDI (Equal Discharge Increment) exige o conhecimento da distribuição da velocidade na vertical e da vazão na seção transversal, dividida em uma série de subseções nas quais há a mesma porção de vazão (SANTOS et al., 2001; CARVALHO, 2008). Para as coletas utilizou-se amostrador de $500 \mathrm{ml}$ e bico de $1 / 4 \mathrm{de}$ polegada, adaptado e fabricado conforme indicado em Watanabe (2015) a partir de garrafas PET, utilizando como modelo o amostrador tipo isocinético, modelo US 
DH-81, conforme Figura 3.

As leituras de turbidez foram realizadas in loco, logo após a coleta, utilizando turbidímetro portátil devidamente calibrado de acordo com as características dos canais analisados. A calibração do turbidímetro foi realizada em amostras (solução) com valores padrões de concentração de sedimentos em suspensão, estabelecendo a relação entre turbidez e concentração de sedimentos. Foram realizadas cinco leituras de turbidez para cada amostra e utilizados os valores médios. Os resultados foram organizados em planilhas para posterior análise estatística e confecção de tabelas e gráficos.

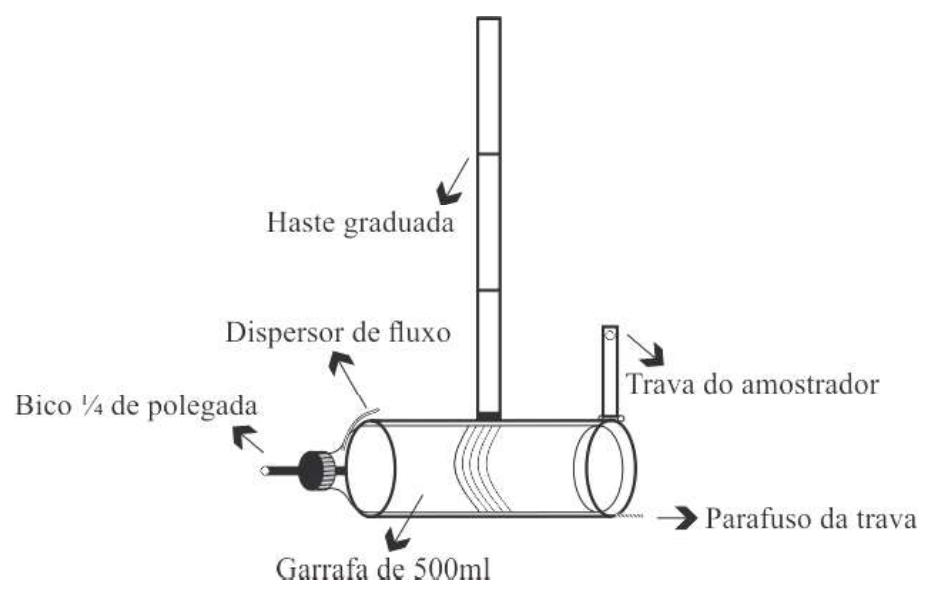

Figura 3 - Amostrador tipo isocinético adaptado do modelo US DH-81.

\section{Quantificação de Sedimentos em Suspensão}

A quantificação de sedimentos em suspensão para as amostras coletadas foi efetuada de acordo com os procedimentos propostos pela ANEEL (2000). Foi filtrado, com bomba de vácuo, o volume de $200 \mathrm{ml}$ de cada amostra em membranas de éster de celulose com porosidade de $0,2 \mu \mathrm{m}$ previamente secas e pesadas (Figura 4). Terminadas as filtragens, as membranas foram secas novamente na mesma temperatura, pelo mesmo período, obtendo-se o peso da membrana seca com sedimento (OLIVEIRA, 2006).

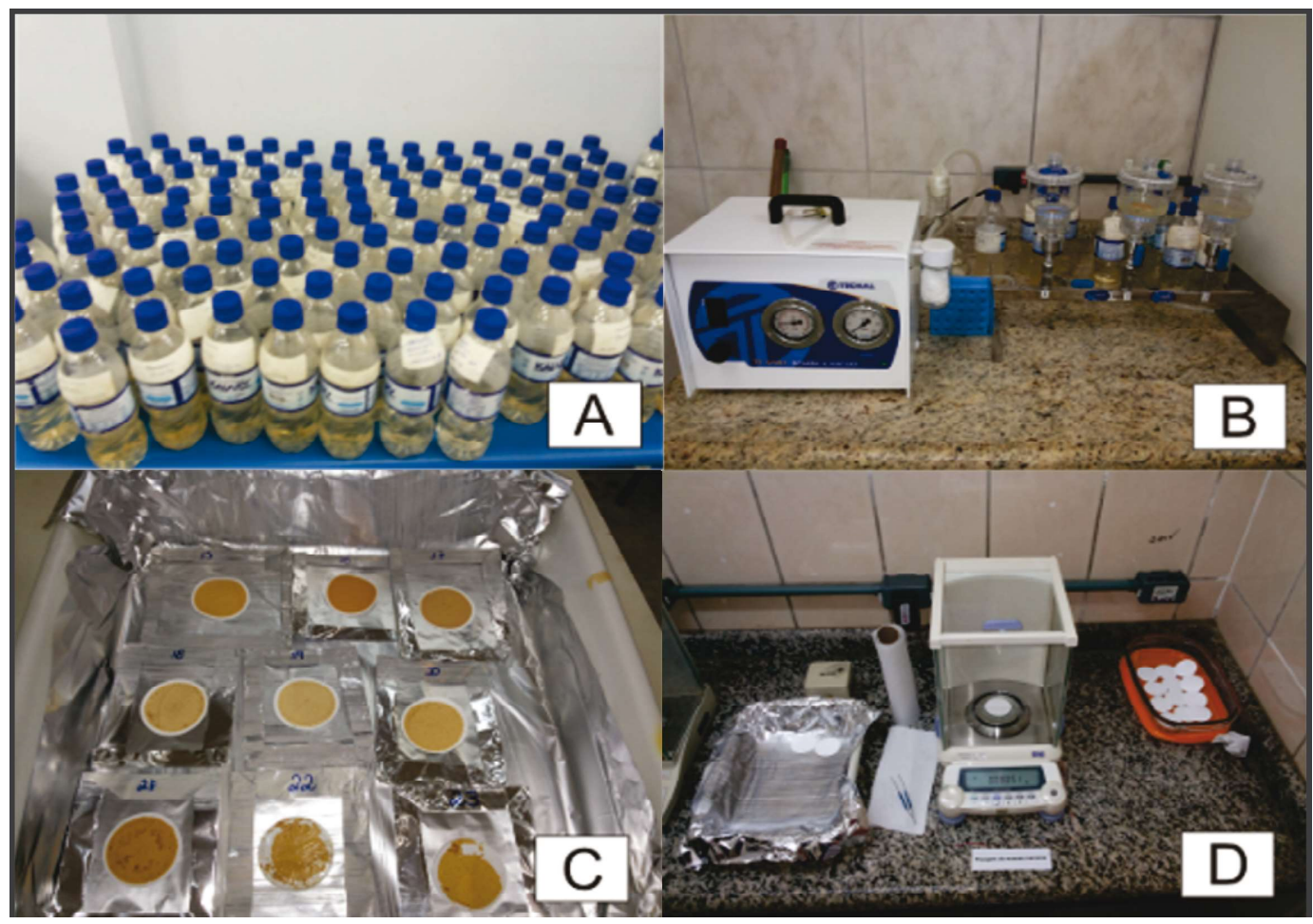

Figura 4 - Procedimento de filtragem em membranas de éster de celulose. 


\section{Uso e Cobertura da Terra}

Para a classificação do uso da terra utilizou-se o método de classificação do Instituto Brasileiro de Geografia e Estatística - IBGE (IBGE, 2006). Após a identificação das possíveis situações da área de estudo, foram definidos, de forma linear e sistemática, pontos para a coleta das informações necessárias, tais como: identificação da área, registro de coordenadas geográficas, tipologia de uso e cobertura da terra e o registro fotográfico. Tais pontos pré-definidos foram plotados em ambiente SIG, juntamente com a imagem de satélite sintetizada e georreferenciada, e dados vetoriais digitais de estradas federais, estaduais e municipais, pavimentadas e não pavimentadas. A linearidade e a identificação dos pontos deram-se, principalmente, nas estradas com intervalos de três quilômetros, num total aproximado de 260 pontos amostrados (WATANABE, 2011).

A classificação foi realizada em ambiente SIG, com uso do software ArcGIS 8.1, utilizando-se da extensão de Classificação Supervisionada. O método utilizado para tal classificação foi o da Máxima Verossimilhança (MaxVer), uma vez que o mesmo considera a ponderação das distâncias das médias e utiliza parâmetros estatísticos (CRÓSTA, 1992).

\section{Resultados}

Para justificar a análise de bacias pareadas, as variáveis devem ser proporcionais em quantidade e distribuição. Os aspectos geológicos, geomorfológicos e os tipos de solo foram os fatores naturais considerados essenciais para a determinação das bacias pareadas. Já o fator primordial que diferencia os resultados e que fornece uma boa comparação entre as variáveis hidrossedimentológicas foi o uso e a cobertura da terra, identificado em campo predominantemente como pecuária e, sendo assim, os comportamentos de cada bacia alteram-se gradativamente de acordo com a intensidade do uso. A classe geológica predominante é o Supergrupo Gnaisse Jaru, a geomorfologia definida como Superfície de Aplanamento, os solos como Latossolo Vermelho-Amarelo Distrófico (TECNOSSOLOS, 2001). Quanto à classe de uso e cobertura da terra, a bacia denominada pecuária apresentou 50,5\% de sua área com pastagem, enquanto que a bacia floresta apresentou $85,3 \%$ de área florestada e padrão drenagem dendrítico.

\section{Dados Pluviométricos}

Para um melhor entendimento do fator chuva na área de estudo, optou-se pelo detalhamento de dois anos de monitoramento direto. A dificuldade de obtenção de dados pluviométricos é referenciada por diversos autores (TUCCI, 2001; ISHIHARA, 2008; FURLAN, 2009) e as limitações nas poucas informações encontradas podem comprometer estudos mais aprofundados sobre a distribuição de chuva local, constatando, assim, que o número de estações por $\mathrm{km}^{2}$ é mais adensado em regiões com os maiores índices populacionais e de melhor acesso via terrestre, em oposição ao que se observou na área de estudo e nas regiões adjacentes da Amazônia Sul Ocidental.

Os registros de chuvas na estação instalada na bacia do rio Mutum-Paraná abrangem o período de janeiro de 2013 a junho de 2015. O período monitorado apresentou em seu decurso algumas variações que devem ser destacadas como, por exemplo, na distribuição das chuvas no período de outubro de 2013 a abril de 2014. Para esse período, verificou-se uma distribuição decrescente nos meses de novembro e dezembro de 2013, com uma ascensão anômala no mês de janeiro de 2014 , com valor de chuva $83,5 \%$ superior ao mesmo mês do ano de 2013 e 79,1\% superior ao ano de 2015 (Figura 5).

Importante destacar que o ano de 2014 foi considerado um ano anômalo em seus registros pluviométricos, intensificados desde áreas mais a oeste (Bolívia) como mais próximas à cidade de Porto Velho. O mês de janeiro de 2014 apresentou as maiores diferenças com, aproximadamente, $200 \mathrm{~mm}$ entre janeiro de 2014 e 2015, $100 \mathrm{~mm}$ entre janeiro de 2013 e 2014, além de $150 \mathrm{~mm}$ em relação à média mensal das estações do Alto rio Madeira. Verifica-se que nos dois períodos de estiagem, que correspondem de julho a agosto, as diferenças foram incisivas. Nos meses de julho e agosto de 2014 observou-se mudança significativa na precipitação pluviométrica, que variou de menos de $10 \mathrm{~mm}$ no mês de julho para $100 \mathrm{~mm}$ no mês de agosto. Esta proporção de distribuição foi para os meses seguintes, o que torna compatível com a tendência regional, conforme TECNOSSOLOS (2001). 


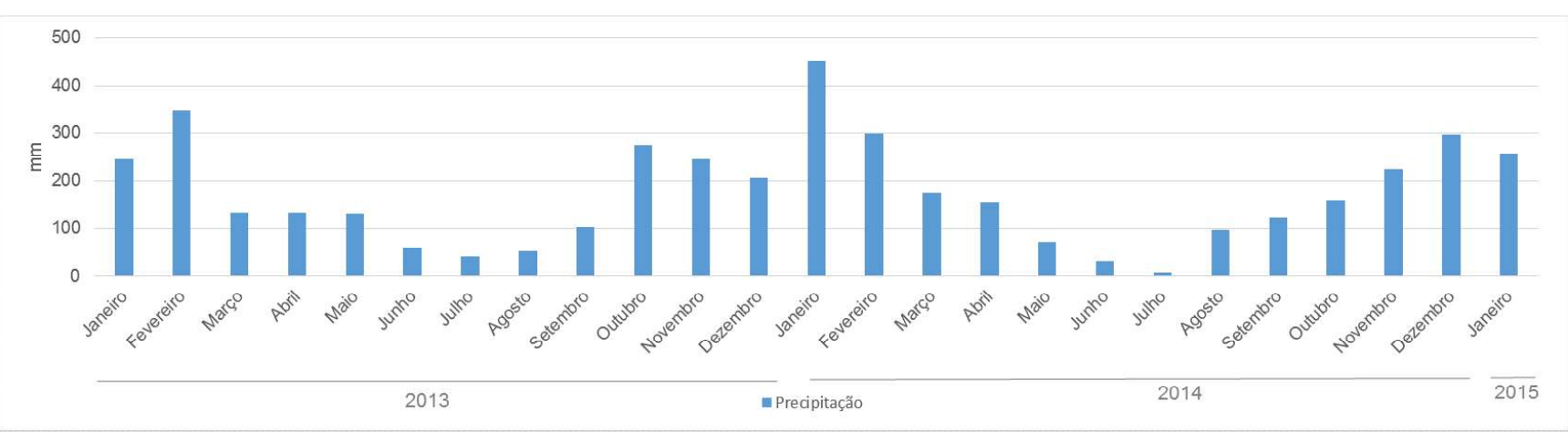

Figura 5 - Precipitação mensal acumulada da estação pluviométrica local 2013-2015.

\section{Monitoramento Mensal}

\section{Vazões}

Assim como o fator chuva, a caracterização das vazões foi realizada no período de 2013-2015. As curvaschave (nível x vazão) para as bacias Floresta e Pecuária foram determinadas de acordo com o monitoramento mensal. Ressalta-se que apenas a foz da bacia MutumParaná possui estação automática com dados a cada 15 minutos de nível e de precipitação, servindo de balizador para compreender o comportamento dos canais das bacias Floresta e Pecuária, além de observador que registrou o valor diário em dois períodos e que favoreceu a interpretação do regime pluviométrico local.

Os períodos de maiores variações das vazões estão concentrados entre os meses de janeiro a abril, apresentando, assim, as características de precipitações intensas e de curto intervalo de tempo. Mesmo considerando registros pontuais mensais, os resultados apontam para respostas bem coerentes entre chuva e vazão, tomando como base os dados pluviométricos e fluviométricos da estação automática local (rio MutumParaná), os registros pluviométricos de anos anteriores e as próprias vazões medidas para cada rio.

\section{Monitoramento de Eventos}

Os eventos pluviométricos analisados ocorreram nos meses de dezembro de 2014 e janeiro de 2015 com coletas de amostras de água e medição de vazão e turbidez horárias.

\section{Eventos (dezembro de 2014)}

Para o mês de dezembro, os registros foram realizados nos dias 20 e 21/12/2014 e mostraram maior oscilação entre as variáveis, principalmente na bacia
Pecuária, com respostas mais significativas nas taxas de sedimento em suspensão e turbidez. A bacia Pecuária apresentou correlação muito forte no dia 20 entre os elementos Sedimento em Suspensão versus Turbidez e Vazão versus Turbidez, caracterizando a recessão do evento pluviométrico registrado (Figura 6).

No dia 20 a turbidez obteve amplitude de 16 NTU (mínima de 102 NTU e máxima de 118 NTU), a vazão oscilou em, aproximadamente, $1,3 \mathrm{~m} / \mathrm{s}$ (mínimo de 2,40 $\mathrm{m}^{3} / \mathrm{s}$ e máxima de $3,67 \mathrm{~m}^{3} / \mathrm{s}$ ) e o sedimento em suspensão apresentou amplitude de $7 \mathrm{mg} / \mathrm{l}$ (mínimo de $27 \mathrm{mg} / \mathrm{l}$ e máximo de $34 \mathrm{mg} / \mathrm{l}$ ). Após a recessão, no dia 21/12, os valores estabilizaram-se com pequenas diferenças entre os registros e com forte correlação. Já para os dois dias analisados em conjunto, verificou-se a rápida oscilação que um evento pode proporcionar na bacia Pecuária, com respostas quantitativas significativas em suas variáveis, obtendo respostas similares conforme estudos realizados por Burch et al. (1987) e Ruprecht e Schofield (1989).

$\mathrm{Na}$ bacia Floresta, para o mesmo evento pluviométrico dos dias 20 e 21/12/2014, verificaram-se melhores correlações entre as variáveis, principalmente no que se refere à vazão. Todas as correlações no dia 20 para a bacia Floresta mostraram-se como forte ou muito forte, cujos registros baixaram proporcionalmente de acordo com a recessão pós-evento. No dia 20 a turbidez variou até 33 NTU (mínima de 68 NTU e máxima de 101 NTU), a quantidade de sedimento em suspensão variou apenas $8,6 \mathrm{mg} / 1$ (mínimo de $23 \mathrm{mg} / \mathrm{l}$ e máximo de $31,6 \mathrm{mg} / \mathrm{l}$ ) e a vazão oscilou entre $1,31 \mathrm{~m}^{3} / \mathrm{s}$ (mínimo de $1,56 \mathrm{~m}^{3} / \mathrm{s}$ e máxima de $2,87 \mathrm{~m}^{3} / \mathrm{s}$ ).

Quando a interferência pelo uso e cobertura da terra está abaixo de $20 \%$ desmatado, verifica-se maior sincronismo entre os elementos vazão, turbidez e sedimento em suspensão. Comparando as duas bacias (Pecuária versus Floresta) notaram-se respostas 
sincronizadas em todos os parâmetros, devido ao evento pluviométrico registrado no dia 20/12. Os valores de turbidez estão sempre elevados para a bacia Pecuária, com um valor médio de 100 NTU e pouca oscilação durante todo o evento. Neste sentido, mesmo apresentando maior oscilação (33 NTU), a bacia Floresta acompanha o ritmo da vazão (recessão), o que não compromete grandes aumentos nas taxas de sedimento em suspensão.

Quanto aos sedimentos em suspensão, a curva da bacia Pecuária está sempre mais elevada em comparação à bacia Floresta. Os registros raramente se cruzam e mantêm amplitudes que podem chegar a $10 \mathrm{mg} / \mathrm{l} \mathrm{em}$ certos momentos do evento, caracterizando a maior carga sedimentar em suspensão carreada pela bacia Pecuária, apresentando resposta mais rápida da saturação dos solos nas pastagens além da intensificação dos fluxos contínuos (BARI et al., 1996; ZIMMERMANN; ELSENBEER; MORAES, 2006).

Ainda sob a influência do período de recessão do evento pluviométrico do dia 20/12, o comportamento das variáveis vazão e sedimento em suspensão no dia 21/12 manteve-se idêntico, havendo variação apenas nos valores de turbidez. Mesmo oscilando apenas 6 NTU, nota-se que a turbidez ainda continuou expressiva na bacia Floresta, e que a estabilização mais abrupta ocorreu na bacia Pecuária. Portanto, o evento do dia anterior promoveu diminuição expressiva da turbidez na bacia Pecuária e pouca oscilação na bacia Floresta, mesmo com diferenças semelhantes de sedimento em suspensão registradas no dia 20/12.

No dia 20/12, a bacia Pecuária apresentou valor médio de sedimento em suspensão de $31 \mathrm{mg} / \mathrm{l}$ e turbidez média de $109 \mathrm{NTU}$, diferindo em apenas $2,7 \mathrm{mg} / \mathrm{l} \mathrm{da}$ bacia Floresta, cuja turbidez média foi de 77,8 NTU. Já no dia 21/12, a bacia Pecuária apresentou valor médio de sedimento em suspensão de $16,1 \mathrm{mg} / \mathrm{l}$ e turbidez média de 52,3 NTU, enquanto que na bacia Floresta o valor médio de sedimento em suspensão foi de apenas $6,5 \mathrm{mg} / \mathrm{l}$ e turbidez média idêntica ao da bacia Pecuária.

Como base comparativa, a bacia do rio MutumParaná apresentou boas correlações para o evento monitorado. A curva de vazão acompanha o evento pluviométrico intenso de $69 \mathrm{~mm}$ (Figura 7), bem como as duas bacias (Pecuária e Floresta). Entretanto, cabe ressaltar que a sensibilidade das duas bacias pareadas (Floresta e Pecuária) é maior do que a bacia Mutum-
Paraná, o que se pode explicar pelo fato da bacia Mutum-Paraná agregar outros canais de drenagem, chegando a $80 \%$ a mais em relação às outras bacias.

Em apenas uma hora de chuva, o acumulado de $39 \mathrm{~mm}$ foi responsável pela ascendência da vazão. O pico da vazão ocorreu duas horas após cessar a precipitação, mantendo-se elevado durante oito horas e retrocedendo lentamente. A diferença da vazão foi de, aproximadamente, $1 \mathrm{~m}^{3} / \mathrm{s}$ durante as 24 horas após o evento, ocasionado pelo tempo-resposta e pela continuidade de chuvas isoladas durante o período. Verificou-se, desta maneira, que os processos hidrossedimentológicos da bacia Mutum-Paraná apresentaram respostas similares em relação à vazão e à precipitação, bem como resposta análoga às bacias Floresta e Pecuária, respeitadas suas áreas de drenagem e suas condicionantes morfométricas e hidrológicas.

\section{Eventos (janeiro de 2015)}

O evento de janeiro de 2015, correspondente ao dia 31/01, apresentou uma ascensão na curva de dados e as correlações foram definidas como forte e muito forte, conforme estudos de Nippes (1983), Pavanelli e Pagliarani (2002), Kliment (2003), entre outros. O período pré-evento (30/01) apresentou forte correlação entre todas as variáveis analisadas na bacia Pecuária, principalmente entre sedimento em suspensão e turbidez, com $\mathrm{R}^{2}=0,94$ (Figura 8).

Apesar da pouca variação da vazão no dia 30/01, os níveis de turbidez apresentaram amplitudes de 20 NTU, e, acompanhando esse ritmo, as taxas de sedimento em suspensão oscilaram em até $6 \mathrm{mg} / \mathrm{l}$. A distribuição de pequenos eventos pluviométricos durante o monitoramento pode explicar esses picos de turbidez durante esse curto intervalo de tempo, bem como as inexpressivas quantidades de sedimentos em suspensão e vazão registradas.

No dia 31/01 o cenário mudou para todas as variáveis, em termos quantitativos, da bacia Pecuária. As correlações se mantiveram em forte e muito forte, evidenciando o período de ascensão do evento pluviométrico com variação na turbidez de 11 NTU e de $10 \mathrm{mg} / \mathrm{l}$ nas taxas de sedimento em suspensão. Mesmo com pequenas amplitudes durante todo o evento, destacaram-se os níveis que cada variável apresentava, como a turbidez com valor médio de 104 NTU e os sedimentos em suspensão com valor médio de $30 \mathrm{mg} / \mathrm{l}$. 
Watanabe M. et al.

\section{Chuva X Sedimento}

$20-21 / 12 / 2014$

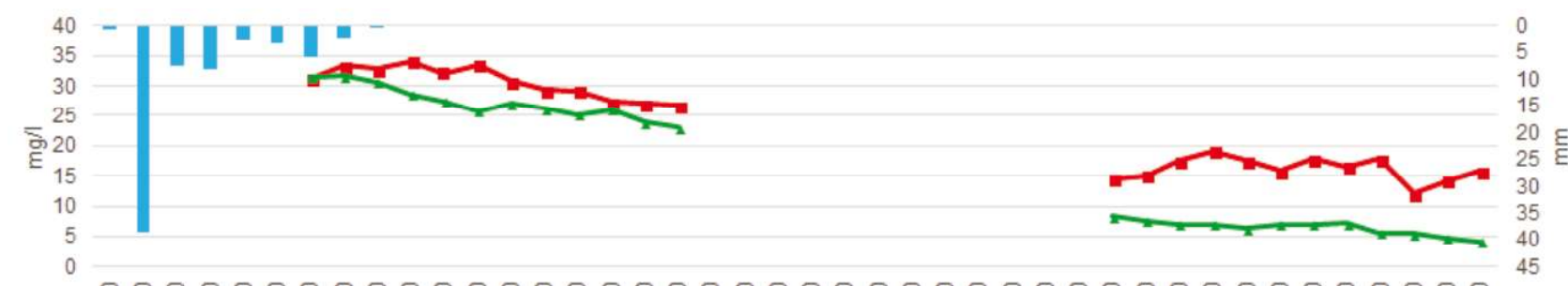

888888888888888888888888888888888888888888 б Chuva $\rightarrow$ Pecuária $\longrightarrow$ Floresta

Chuva X Turbidez

$20-21 / 12 / 2014$

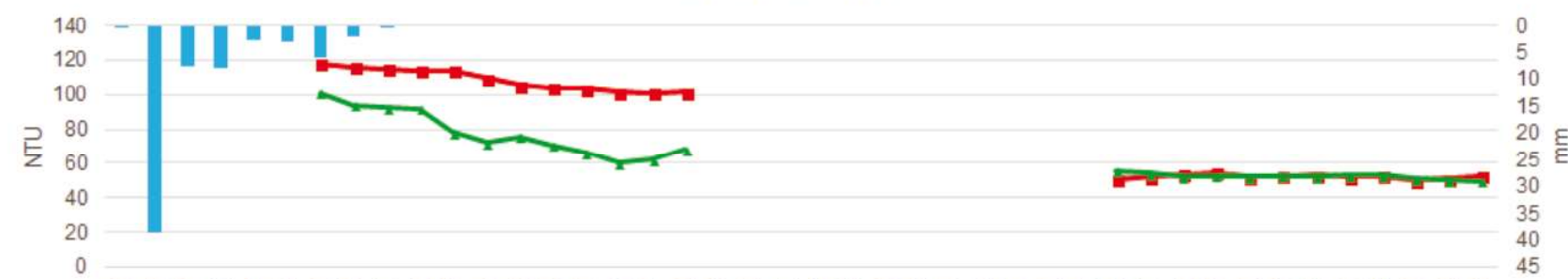

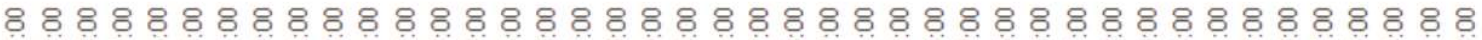

ர்

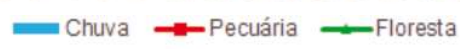

Chuva X Vazão

20-21/12-2014

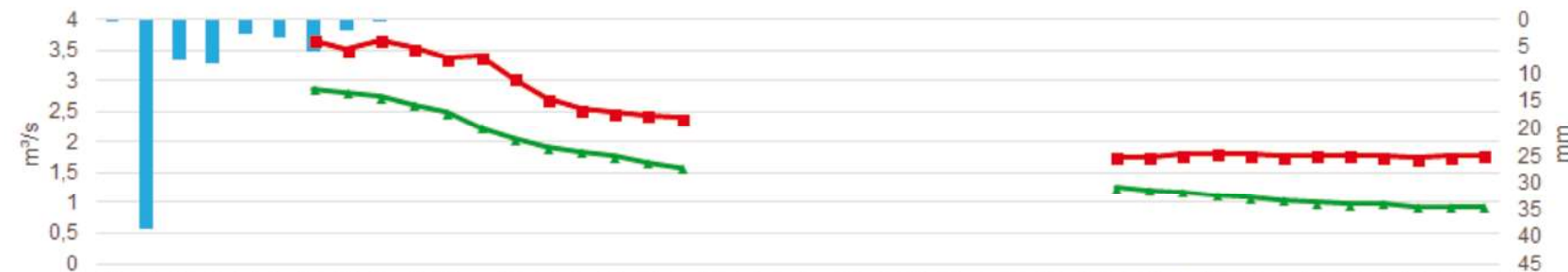

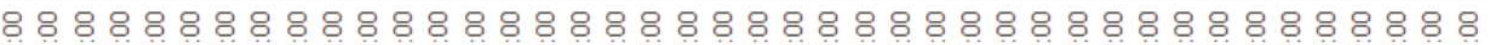

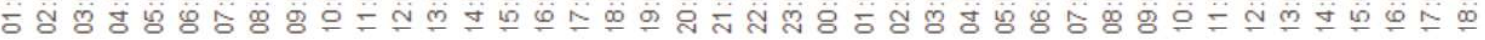

Chuva $\rightarrow$ Pecuária $\longrightarrow$ Floresta

Figura 6 - Relação dos parâmetros chuva-vazão-sedimento-turbidez entre as bacias Floresta e Pecuária em dezembro de 2014.

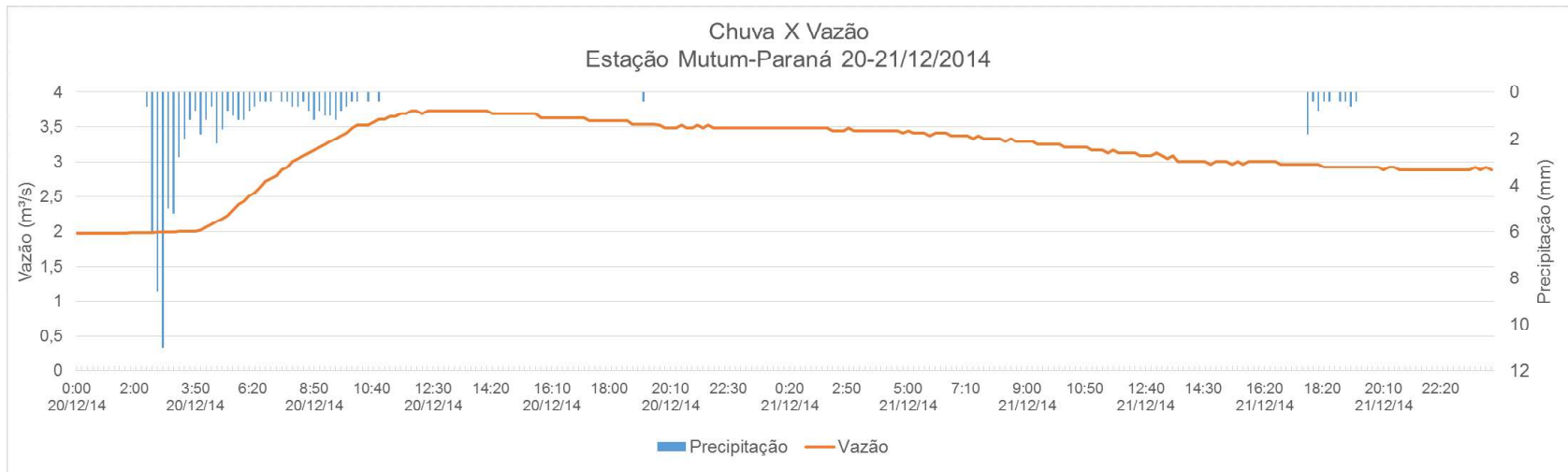

Figura 7 - Hidrograma do evento pluviométrico nos dias 20-21/12/2014 da bacia do rio Mutum-Paraná para fins de comparação. 
Para o mesmo evento, as correlações da bacia Floresta apresentaram-se como forte e muito forte, e com variações entre os elementos turbidez e sedimento em suspensão similar à bacia Pecuária. O pré-evento
(30/01) apresentou amplitude nas taxas de turbidez de 7 NTU e de $5 \mathrm{mg} / \mathrm{l}$ nos registros de sedimento em suspensão, denotando maior regularidade nos processos hidrológicos.

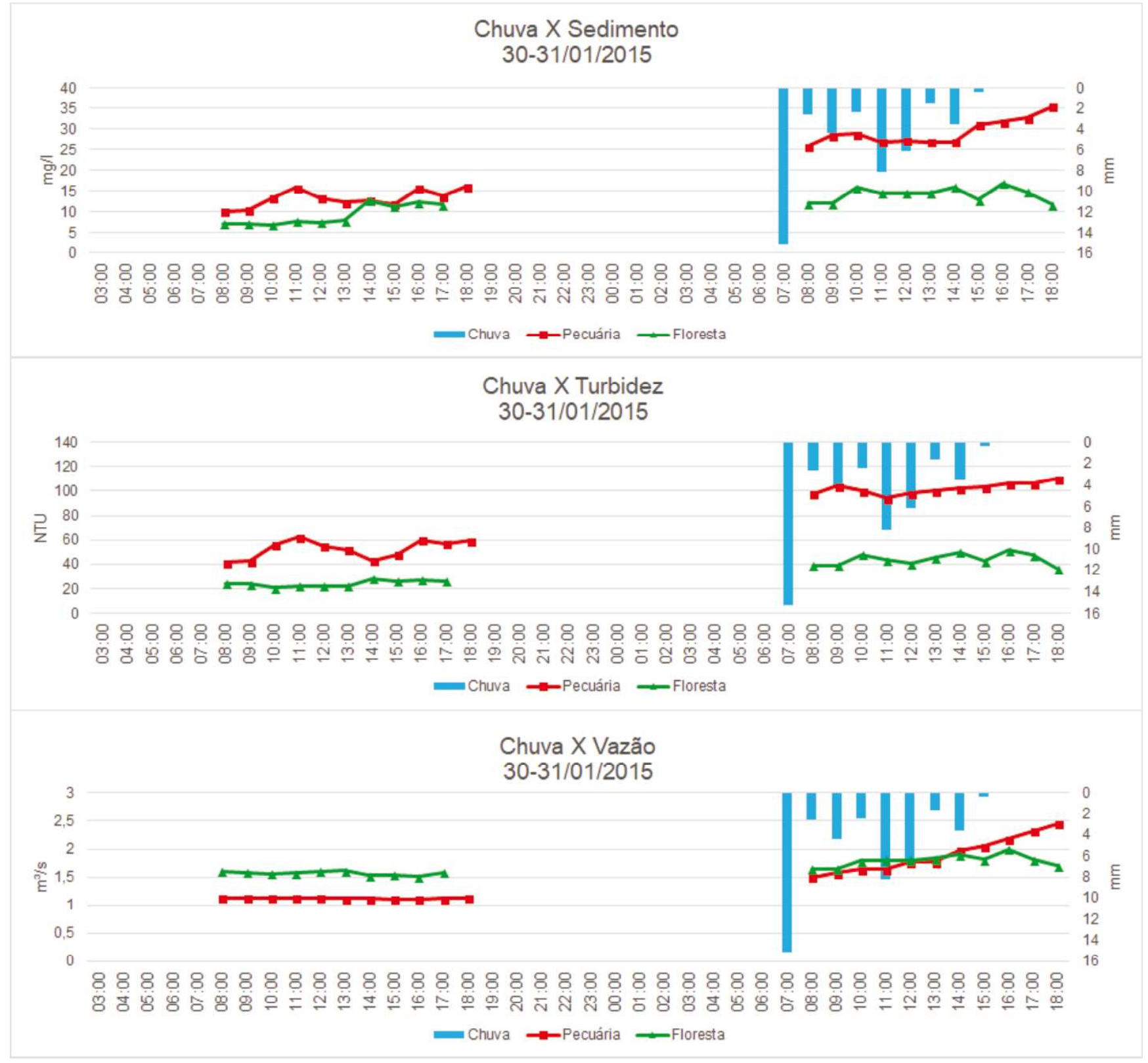

Figura 8 - Relação dos parâmetros chuva-vazão-sedimento-turbidez entre as bacias Floresta e Pecuária em janeiro de 2015.

Diferente do evento registrado no mês de dezembro de 2014, as oscilações registradas no dia 31/01/2015 foram inferiores, cujas variações de amplitude nas taxas de sedimento em suspensão foram de $5 \mathrm{mg} / \mathrm{l}$ e a turbidez de 15 NTU. Mesmo com a ascendência dos registros pluviométricos, a vazão mostrou maior oscilação durante o período monitorado e com amplitude apenas de $0,4 \mathrm{~m}^{3} / \mathrm{s}$, definindo a bacia floresta com controle em seus elementos hidrossedimentológicos e evidenciando o efeito da pouca interferência no canal fluvial. 
O comparativo entre as bacias nos dias 30 e $31 / 01$ evidencia as diferenças, principalmente, entre os sedimentos em suspensão e a turbidez. No dia 30/01 a bacia Pecuária apresentou um valor médio de sedimento em suspensão de 13,26 mg/l e turbidez média de 52,5 NTU, enquanto que, no mesmo período, a bacia Floresta apresentou média de 9,27 mg/l e valores médios de turbidez de 24 NTU.

No dia $31 / 01$ os valores médios de turbidez e de sedimentos em suspensão aumentaram significativamente em virtude do evento pluviométrico (ascensão) registrado. Na bacia Pecuária, os valores médios de sedimento em suspensão foram de 29,3 $\mathrm{mg} / \mathrm{l}$ e o valor médio de turbidez de $102 \mathrm{NTU}$, o que diferiu dos valores encontrados na bacia Floresta, cujos registros de sedimento em suspensão foram de 14,2 mg/1 e valor de turbidez média de 44 NTU, evidenciando o que afirma Bonell, Gilmore e Cassells (1983) e Ruprecht e Schofield (1989), na qual a manutenção da floresta resulta no controle dos fluxos subsuperficiais e superficiais.
A resposta do evento pluviométrico registrado pela estação automática Mutum-Paraná, do dia 31/01/2015, mostrou-se diferente do evento de dezembro de 2014, obtendo valor de $44,6 \mathrm{~mm}$, além de menor intensidade. Tal comportamento refletiu diretamente na curva de vazão, que apresentou oscilação de apenas $0,4 \mathrm{~m}^{3} / \mathrm{s}$. Além disso, esse pequeno pico de vazão durou 13 horas até alcançar seu ápice, sendo restabelecido gradualmente (Figura 9).

\section{Discussões}

Comparando-se os valores de sedimento em suspensão com os eventos pluviométricos, verificaramse diferenças significativas em relação a outras bacias. Conforme trabalho de López-Tarazón et al. (2010), as chuvas mais concentradas em sua área de estudo não apresentaram valores significativos em relação a esse estudo, o que evidencia a sensibilidade das bacias estudas neste trabalho, assim como a intensidade das chuvas da região amazônica.

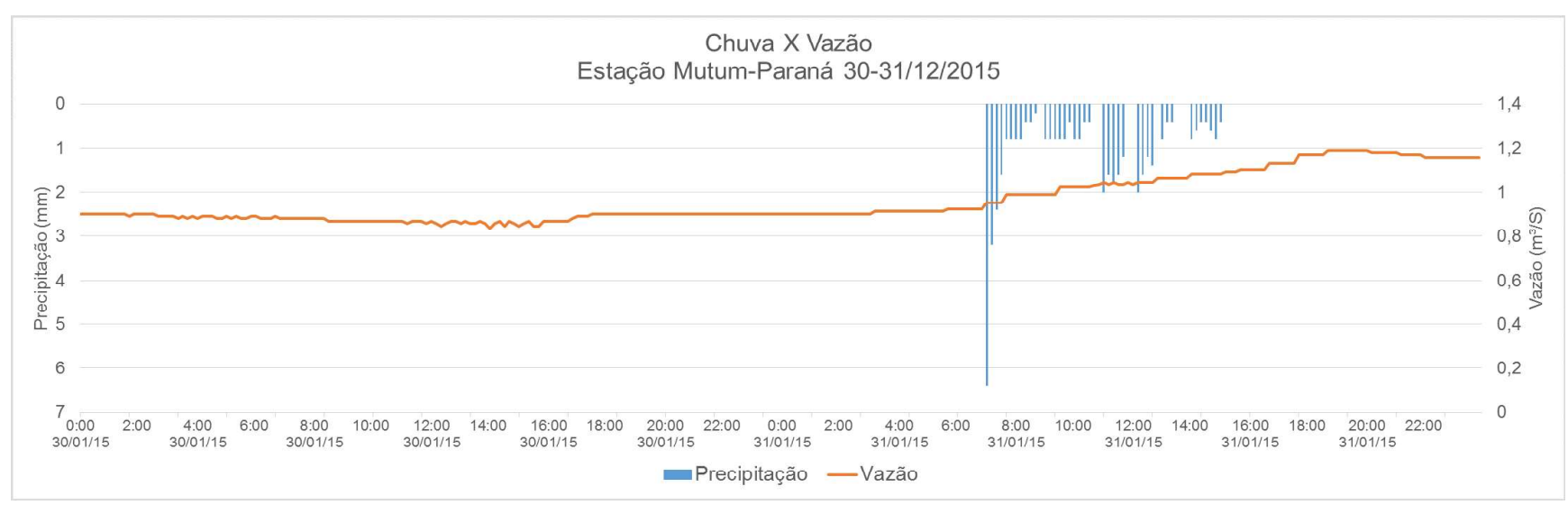

Figura 9 - Hidrograma do evento pluviométrico nos dias 30-31/12/2015 da bacia do rio Mutum-Paraná para fins de comparação.

Nesta escala de análise, a bacia Mutum-Paraná apresentou comportamento diferenciado, justificado pela dimensão da bacia e o tempo de concentração. Estas apresentaram sensibilidade considerável elevando os valores das variáveis hidrossedimentológicas, com destaque para a vazão e a turbidez que mantiveram uma resposta ascendente em relação ao evento pluviométrico. Durante os eventos, o tempo de concentração de bacias, como a Pecuária e a Floresta, tende a seguir o ritmo e a magnitude das chuvas, não havendo atrasos significativos na vazão e na concentração de sedimentos em suspensão. O fator uso e cobertura da terra é quem determinará, para bacias desse porte, a maior elevação dos valores hidrossedimentológicos (SOLER; LATRON; GALLART, 2008; ESTRANY; GARCIA; BATALLA, 2009).

Verificou-se, desse modo, que eventos pluviométricos com baixa intensidade são mais expressivos em bacias menores, não importando o uso e cobertura da terra, isto é, canais mais desenvolvidos e com maiores áreas de drenagem, mesmo com usos distintos, tendem a apresentar maior controle da vazão. Isto implica, necessariamente, na diminuição de valores de outros elementos, como a turbidez e a concentração 
de sedimentos em suspensão, conforme verificado em levantamento realizado por Brown et al. (2005) em bacias pareadas nos continentes europeu, asiático e africano, bem como na Austrália.

Os dois eventos pluviométricos registrados em dezembro de 2014 e janeiro de 2015 mostraram-se condizentes com as taxas de sedimento em suspensão. $\mathrm{O}$ evento pluviométrico de dezembro de 2014 apresentou valor acumulado de $69 \mathrm{~mm}$ e média de 1.908,94 ton/ano para a bacia Floresta, o que representa 34,14 ton/ano/ $\mathrm{km}^{2}$. Para a bacia Pecuária, o mesmo evento representou $2.961,9$ ton/ano, com 68,43 ton $/ \mathrm{ano} / \mathrm{km}^{2}$. Já no evento pluviométrico de janeiro de 2015, cujo valor acumulado foi de 44,6 mm, o registro de sedimento em suspensão na bacia Floresta foi de 796,8 ton/ano, apresentando 14,25 ton $/ \mathrm{ano} / \mathrm{km}^{2}$, enquanto que a bacia Pecuária registrou média de $1.721,23$ ton/ano, com 39,78 ton $/ \mathrm{ano} / \mathrm{km}^{2}$. Desse modo, verifica-se que o evento pluviométrico de $31 / 01 / 2015$, correspondendo a $64,63 \%$ do evento pluviométrico de 20/12/2014, levou a uma diferença de sedimento em suspensão entre os dois eventos de $139,57 \%$ na bacia Floresta e de $72,08 \%$ na bacia Pecuária. Essa amostragem demonstra a amplitude e a intensidade dos eventos pluviométricos amazônicos associados ao desmatamento e uso intensivos (pastagem) na região. Quando comparados a outros estudos, mesmo conforme suas peculiaridades regionais, ou seja, geomorfologia mais acentuada somada a eventos pluviométricos mais intensos (EMBRAPA, 2004; OLIVEIRA, 2006; VANACKER et al., 2007; CABRAL et al., 2009; TENA et al., 2011) apresentaram taxas de sedimentos em suspensão inferiores.

\section{Conclusões}

Em condições muito similares em termos geométricos, enquanto forma, dimensão e estrutura, as bacias Floresta e Pecuária apresentaram valores hidrossedimentológicos distintos, o que evidencia a interferência do uso e cobertura da terra nos parâmetros vazão, turbidez e sedimentos em suspensão.

O desmatamento e o uso de pastagem em bacias hidrográficas desse porte apresentam taxas de sedimentos em suspensão, turbidez e velocidade de fluxo do canal bastante superiores às bacias com cobertura vegetal natural. Isso corrobora a importância das áreas florestadas para a região amazônica e implica em medidas que alterem a forma agressiva que esse tipo de uso da terra promove. As elevadas taxas de desmatamento anuais na Amazônia, associadas, principalmente, na implantação de novas áreas para o desenvolvimento da pecuária, podem promover grandes perdas para o ecossistema regional, tais como diminuição do volume de água, assoreamento de canais fluviais, perda da qualidade da água, etc.

Por fim, verifica-se que a concentração de sedimentos em suspensão para as bacias pareadas estudadas eleva-se com a intensificação do uso de pastagem. Diferenças de aproximadamente 38\% (202,37 ton/ano) a mais de carga sedimentar em suspensão durante os meses monitorados (2013-2015) mostram que as respostas hidrossedimentológicas tendem a elevar seus valores no decorrer da expansão da pastagem. As amostragens por eventos pluviométricos mostram um cenário ainda mais grave, pois apresentam diferenças bastante significativas que variam em virtude da magnitude dos eventos; são valores que chegam a ultrapassar $315 \%$ de aumento em comparação com as bacias pareadas. Portanto, bacias desse porte tendem a ser mais sensíveis, mesmo em eventos pluviométricos menos intensos e melhor distribuídos temporalmente.

\section{Referências Bibliográficas}

ANEEL (2000) Guia de práticas sedimentométricas. Publicação ANEEL. 116 p.

BARI, M. A.; SMITH, N.; RUPRECHT, J. K.; BOYD, B.W. Changes in streamflow components following logging and regeneration in the southern forest of Western Australia. Hydrological Processes, v. 10, n. 3, p. 447-461, 1996. DOI: 10.1002/(SICI)1099-1085(199603)10:3<447::AIDHYP431>3.0.CO;2-1.

BECKINSALE, R. P. (1973). River Regimes. In: CHORLEY, R. J. (org.). Introduction to Physical Hydrology. Methuen \& Co. Ltd., Bungay: p. 176-192.

BONELL, M.; GILMORE, D. A.; CASSELLS, D. S. Runoff generation in tropical northeast Queensland, Australia, and the implications for land use management. Hydrology of humid tropical regions with particular reference to the hydrological effect to agriculture and forestry practice. Proceedings of Hamburg Symposium. IAHS Publication, v. 1, n. 140, p. $287-$ 297, 1983.

BOSCH, J. M.; HEWLETT, J. D. A review of catchment experiment to determine the effect of vegetation changes on 
water yield and evapotranspiration. J. Hydrology, v. 55, n. 1-4, p. 3-23, 1982. DOI: 10.1016/0022-1694(82)90117-2.

BROWN, A. E.; ZHANG, L.; MCMAHON, T. A.; WESTERN, A. W. VERTESSY, R. A. A review of paired catchment studies for determining changes in water yield resulting from alterations in vegetation. J. Hydrology, v. 310, n. 1, p. 28-61, 2005. DOI: 10.1016/j.jhydrol.2004.12.010.

BRUIJNZEEL, L. A. Hydrology of moist tropical forests and effects of conversion: a state of knowledge review. Paris: IHPUNESCO, 1990. 224p.

BRUIJNZEEL, L.A. (1996). Predicting the hydrological impacts of land cover transformations in the humid tropics: the need for integrated research. In: GASH, J. H. C. (org.). Amazonian Deforestation and Climate. J. Wiley \& Sons, New York: p. 15-55.

BURCH, G. J.; BATH, R. K.; MORE, I. D.; O'LOUGHLIN, E. M. Comparative hydrological behavior of forested and cleared catchments in southeastern Australia. J. of Hydrology, v. 90, n. 1-2, p. 19-42, 1987. DOI: 10.1016/0022-1694(87)90171-5.

CABRAL, J. B. P.; FERNANDES, L. A.; BECEGATO, V. A.; SILVA, S. A. da. Concentração de sedimentos suspensão: reservatório de Cachoeira Dourada-GO/MG, Brasil. Mercator, v. 1, n. 16, p. 233-253, 2009. DOI: 10.4215/RM2009.0816.0018.

CARVALHO, N. O. Hidrossedimentologia prática. 2. ed. Rio de Janeiro: Interciência, 2008. 600p.

CAVAlCANTE, M. M. A.; NUNES, D. D.; SILVA, R. G. C.; LOBATO, L. C. H. Políticas Territoriais e Mobilidade Populacional na Amazônia: contribuições sobre a área de influência das Hidrelétricas no Rio Madeira (Rondônia/Brasil). Rev. Confins [Online], v. 11, n. 1, p. 1-17, 2011. DOI: dx.doi. org/10.4000/confins.6924.

CHORLEY, R. J. Geomorphology and general systems theory. U.S. Geol. Survey Prof. Paper, v. 500-B, n. 1, p. 1-10, 1962.

CHRISTOFOLETTI, A. Geomorfologia fluvial. São Paulo: Edgard Blücher, 1981.313p.

CRÓSTA, A. P. Processamento digital de imagens de sensoriamento remoto. Campinas: Instituto de Geociências/ UNICAMP, 1992. 170p.

DUVERT, C.; GRATIOT, N.; EVRARD, O.; NAVRATIL, O.; NÉMERY, J.; PRAT, C.; ESTEVES, M. Drivers of erosion and suspended sediment transport in three headwater catchments of the Mexican Central Highlands. Geomorphology, v. 123, n. 3, p. 243-256, 2010. DOI: 10.1016/j.geomorph.2010.07.016.
EMBRAPA (2004) Diagnóstico do fluxo de sedimentos em suspensão na Bacia Araguaia-Tocantins. Publicação EMBRAPA. 116 p.

ESTRANY, J.; GARCIA, C. J.; BATALLA, R. Groundwater control on the suspended sediment load in the Na Borges River, Mallorca, Spain. Geomorphology, v. 106, n. 3, p. 292-303, 2009. Disponível em: DOI: doi.org/10.1016/j.geomorph.2008.11.008.

FILIZOLA, N.; GUYOT, J.-L. Fluxo de sedimentos em suspensão nos rios da Amazônia. Revista Brasileira De Geociências, v. 41, n. 4, p. 566-57, 2011.

FURLAN, D. N. Variabilidade temporal e espacial das chuvas e do balanço hídrico no estado de Rondônia: caracterização e análise de tendência. Dissertação (Mestrado em Física do Ambiente Agrícola). Escola Superior de Agricultura Luiz de Queiroz, Universidade de São Paulo. Piracicaba. 2009. 129 p.

GUYOT, J. L. Hydrogéochimie des Fleuves de l'Amazonie Bolivienne. Paris. ORSTOM/Coll. Etudes et Thèses, 1993. 259p. IBGE (1996) Manual técnico de uso da terra. Publicação $n^{\circ}$ 2. $171 \mathrm{p}$.

ISHIHARA, J. H. Avaliação quantitativa e espacial da precipitação na Amazônia brasileira (Amazônia legal) no período de 30 anos, de 1978 a 2007. Dissertação (Mestrado em Engenharia Civil). Universidade Federal do Pará. Belém. 2008. 104 p.

KLIMENT, Z. Transport of suspended sediments in various regions of the Czech Republik. Acta Universitatis Carolinae - Geographica, v. 1, n. 1, p. 157-166, 2003.

LÓPEZ-TARAZÓN, J. A.; BATALLA, R. J.; VERICAT. D.; BALASCH, J. C. Rainfall-runoff-sediment transport relations in a large mountainous catchment: the river Isábena (Ebro basin). Catena, v. 1, n. 82, p. 23-34, 2010. DOI: 10.1016/j. catena.2010.04.005.

NIPPES, K. R. Erfassung von Schwebstoff transporten in Mittelgebirgsflüssen. Geoökodynamic, v. 1, n. 4, p. 105-124, 1983.

NUNES, D. D.; CAVALCANTE, M. M. A.; LOBATO, L. C. H. (2011). Novas Configurações e Novos Desafios na Amazônia Sul Ocidental: reflexos dos grandes empreendimentos em Rondônia. In: CARAMELLO, N. D. A.; CARNIATTO, I.; PINHEIRO, Z. C.; MARÇAL, M. S. (orgs.). Amazônia: recursos hídricos e diálogos socioambientais. Ed. CRV, Curitiba: p. 79-86.

NUNES, D. D.; WATANABE, M.; NUNES, A. C. S.; CAVALCANTE, M. M. A. (2015). Formação socioambiental do estado de Rondônia. In: SIMONIAN, L. T. L.; BAPTISTA, 
E. R. (orgs.). Formação socioambiental da Amazônia. Editora do NAEA, Belém: p. 527-622.

OLIVEIRA, F. A. de. Estudo do aporte sedimentar em suspensão na Baía da Babitonga sob a ótica da geomorfologia. Tese (Doutorado em Geografia Física). Faculdade de Filosofia, Letras e Ciências Humanas, Universidade de São Paulo, São Paulo. 2006. 286p.

PAVANELLI, D.; PAGLIARANI, A. Monitoring water flow, turbidity and suspended sediment load from an apennine catchment basin, Italy. Biosystems Engeneering, v. 83, n. 4, p. 463-468, 2002. DOI: 10.1006/bioe.2002.0126.

PIÉGAY, H.; SCHUMM, S. A. (2003). System approaches in fluvial geomorphology. In: KONDOLF, G. M.; PIÉGAY, H. (orgs.). Tools in Fluvial Geomorphology. John Wiley \& Sons, Chichester: p. 103-132.

RIVERO, S.; ALMEIDA, O.; AVILA, S.; OLIVEIRA, W. Pecuária e desmatamento: uma análise das principais causas diretas do desmatamento na Amazônia. Rev. Nova Economia, Belo Horizonte, v. 19, n. 1, p. 41-66, 2009. DOI: dx.doi. org/10.1590/S0103-63512009000100003.

RUPRECHT, J. K.; SCHOFIELD, N. J. Analysis of streamflow generation following deforestation in southwest Western Australia. J. of Hidrology, v. 105, n. 1-2, p. 1-17, 1989. DOI: 10.1016/0022-1694(89)90093-0.

SANTOS, I.; FILL, H. D.; SUGAI, M. R. V.; BUBA, H.; KISHI, R. T.; MARONE, E.; LAUTERT, L. F. C. Hidrometria aplicada. Curitiba: Instituto de Tecnologia para o Desenvolvimento, 2001. 372 p.

SILVA FILHO, E. P. da. Estudo da degradação dos solos em áreas de pastagens no município de Porto Velho (RO). Tese (Doutorado em Geociências e Meio Ambiente - IGCE). Universidade Estadual Paulista, Rio Claro. 2009. 159p.

SOLER, M.; LATRON, J.; GALLART, F. Relationships between suspended sediment concentrations and discharge in two small research basins in a mountainous Mediterranean area (Vallcebre, Eastern Pyrenees). Geomorphology, v. 1, n. 98, p. 143-152, 2008. DOI: 10.1016/j.geomorph.2007.02.032.

STEDNICK, J. D. Monitoring the effects of timber harvest on annual water yield. J. Hydrology, v. 1, n. 176, p. 79-95, 1996.
DOI: $10.1016 / 0022-1694(95) 02780-7$.

TECNOSSOLOS (2001) Plano Agroflorestal de Rondônia PLANAFLORO. Relatório Técnico. Publicação n. 13, 160p.

TENA, A.; BATALLA, R. J.; VERICAT, D.; LÓPEZTARAZÓN, J. A. Suspended sediment dynamics in a large regulated river over a 10-year period (the lower Ebro, NE Iberian Peninsula). Geomorphology, v. 1, n. 125, p. 73-84, 2011. DOI: 10.1016/j.geomorph.2010.07.029.

TRICART, J. Método de estudos hidrológicos. Salvador: Publicações da Universidade da Bahia, 1960. 15p.

TUCCI, C. E. M. Hidrologia. 2. ed. Porto Alegre: Editora da UFRGS, 2001. 943p.

VANACKER, V.; MOLINA, A.; GOVERS, G.; POESEN, J.; DECKERS, J. Spatial variation of suspended sediment concentrations in a tropical Andean river system: The Paute River, southern Ecuador. Geomorphology, v. 1, n. 87, p. 53-67, 2007. DOI: 10.1016/j.geomorph.2006.06.042.

VERICAT, D., BATALLA, R. J. Sediment transport in a large impounded river: the lower Ebro, NE Iberian Peninsula. Geomorphology, v. 1, n. 79, p. 72-92, 2006. DOI: 10.1016/j. geomorph.2005.09.017.

VERTESSY, R. A. (2000). Impacts of plantation forestry on catchment runoff. In: LOUGHLIN, O. E.; NAMBIAR, E. K. S. (orgs.). Plantations, farm forestry and water. CSIRO/RIRDC, Kingston: p. 1-9.

WATANABE, M. Análise Integrada da Paisagem da bacia do rio Mutum-Paraná. Dissertação (Mestrado em Geografia). Programa de Pós-Graduação em Geografia, Universidade Federal de Rondônia. Porto Velho. 2011. 106p.

WATANABE, M. O Uso da Terra e o aporte sedimentar em suspensão se Bacias Pareadas na Amazônia: sub-bacias do rio Mutum-Paraná/RO. Tese (Doutorado em Geografia). Universidade Federal do Paraná. Curitiba. 2015. 115 p.

ZIMMERMANN, B.; ELSENBEER, H.; MORAES, J. M. The influence of land-use changes on soil hydraulic properties: Implications for runoff generation. Forest Ecology and Management, v. 222, n. 1, p. 29-38, 2006. DOI: 10.1016/j. foreco.2005.10.070. 